\title{
Private Sector Metrics Contributions to Social Change: Customer Satisfaction Meets Agriculture Development
}

\author{
David Bonbright and Jamey Power
}

\begin{abstract}
The ambitious current wave of agriculture development projects - public, private and publicprivate - expressly profess to break with 60 years of underperformance in support for smallholder agriculture in Africa and South Asia. These projects share with their discredited predecessors a supply-side approach that seeks to introduce something exogenous to improve agriculture outcomes. The introduced factors vary, including improved seeds to fertilisers to pest control and resource management to other agronomic techniques to supply chain efficiencies, improved production technologies, to better market access. The list goes on, driven by the technological ingenuity and commitment of highly educated agriculture specialists from the Global North. This article argues that these bold supply-side efforts run the risk of badly underperforming or even failing unless they build in real accountability to the intended beneficiaries - smallholder farmers - through systematic feedback loops. The argument draws from the business management canon of customer satisfaction.
\end{abstract}

\section{Introduction}

As is well-argued in several other articles in this IDS Bulletin, weak monitoring and evaluation practices in the field of agriculture development are explained by a wicked combination of external conditions - nature-induced uncertainty, long impact pathways, a multiplicity of actors (farmers, scientists, extension agents, policymakers), and most importantly, the fact that those meant to benefit have little voice or choice over the projects operated in their names.

Of these factors, the one most susceptible to redress is that of farmer voice, and over the past 60 years a distinguished history of innovation to enhance farmer participation and voice in agriculture development projects has produced a range of 'participatory' methodologies for planning, implementation, monitoring and evaluation. These methodologies have not spread as wide or as deep as is required to shift the centre of gravity in agriculture development management practices from being more supplydriven than demand-driven. While there are many reasons for this, the absence of strong external incentives - such as the requirements of funders and regulators - is clearly a key impediment.

The early history of the customer satisfaction industry is apposite here. In the 1950s the field of market research did not focus on customer satisfaction. It was only after the consumer rights movement gained political clout, and the US government passed a series of laws to 'protect the consumer interest' under President Kennedy's leadership in 1962, did what we now know as customer satisfaction research begin. ${ }^{2}$ As consumers became more demanding, and as the law recognised those demands, market researchers saw an opportunity and began to collect and sell information on consumer satisfaction to companies.

Over the past 50 years 'customer satisfaction' specialists have transformed a number of industries and established widely accepted societal norms of corporate responsiveness to consumers. The field has a large literature that

IDS Bulletin Volume 41 Number 6 November 2010 C 2010 The Authors. Journal compilation ( Institute of Development Studies Published by Blackwell Publishing Ltd, 9600 Garsington Road, Oxford OX4 2DQ, UK and 350 Main Street, Malden, MA 02148, USA 
can be studied profitably by those seeking to benefit poor smallholder farmers. ${ }^{3}$

To reference a few prominent examples, customer satisfaction research has dramatically improved the automotive industry, both in terms of product quality and in satisfaction with dealers. ${ }^{4}$ As a direct result of published customer feedback, the market 'forced out' poorer performing auto brands or they lost sales volume (Denove and Power 2006). Consumer satisfaction with new homebuilders has improved - and caused the whole industry to improve (J.D. Power and Associates 2009). Many companies have reversed their fortunes by becoming obsessive about customer satisfaction, with one welldocumented example being that of Continental Airlines (Bethune 1998). Brands like Hyundai in the USA found 'religion' after dismal years of poor quality and then declining sales, and turned around their prospects by focusing on quality and product satisfaction.

It is not easy to imagine that specific historical pattern being repeated in the arena of agriculture development. Smallholder farmers in Africa do not have the choices or disposable income of middle-class consumers in the USA. We are not about to see legislation mandating that international aid beneficiaries' interests be codified in legal rights and entitlements since by definition aid beneficiaries do not vote in donor countries. Their own governments should in theory be the ones to protect their interests, but in practice this is not a priority in the scramble to win international aid.

The aid industry is fundamentally different from the business sector in another way. Businesses do not need to be persuaded to pay attention to their customers because those that do, go out of business. The competitive market system has driven businesses in a relentless process of rigorous management to performance outcomes in order to survive and thrive.

Non-profit organisations have yet to make the shift to rigorous outcomes-based management, let alone paying rigorous attention to their ultimate 'customers' - the people that are meant to benefit from their work. Since the shift to managing by actual outcomes requires a fundamental transformation in the management cultures of agriculture development organisations, the difficulties of making this shift in the absence of competitive incentives are formidable. Organisational culture change is always difficult (see Oswald and Taylor, this IDS Bulletin). Some of the obstacles include:

- Few, if any, examples of effective outcome management - and in our case, farmer feedback systems (see Jacobs, this IDS Bulletin)

- Few, if any, financial rewards for successful adoption of farmer voice methods

- Risks associated with 'first mover' discovery of farmer dissatisfaction

- Limited budget and organisational capacity to pilot farmer voice methods

- Little strategic assistance and tools to encourage agriculture development managers to take up these approaches.

But two things are happening that may just combine to make it possible to see a widespread shift in favour of farmer voice. One is a consequence of an increasing insistence by the funders of development on better evidence of results. As this emphasis spreads and gains traction, it gathers sophistication about the relationship between assessment, on the one hand, and performance management and corrective improvement on the other. As this happens, it will become clear that the best available real-time indicator of performance is farmer voice. It is already clear that rewards will come to those agriculture development organisations that build evidence of effectiveness into their performance management systems. In the future, those showing clear demand-side indicators such as those generated through 'voice of the farmer' activities will be well rewarded by the donor community (see Jacobs; and Haddad et al., this IDS Bulletin).

The second thing that is happening to support this trend is that technology is driving down the cost of collecting feedback systematically from even the poorest farmers. Using community radio, cell phones, and webs of volunteer feedback gatherers it is possible to reach people who historically could only be reached through expensive household interviews. As Jacobs in this IDS Bulletin indicates, this wave of innovation in communications technology is gaining force and can now be used to cultivate farmer voice.

In support of these trends, this article will now proceed to use a hypothetical example to 
Figure 1 Three constituent groups

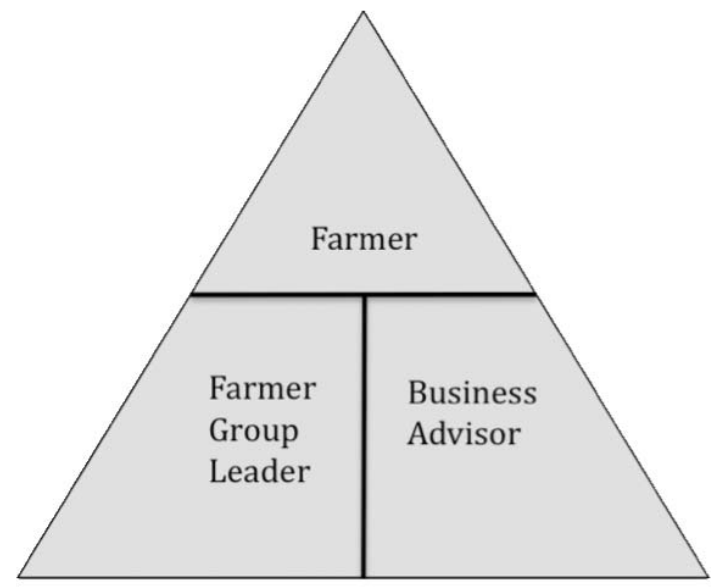

illustrate what can happen when one applies the business craft of customer satisfaction to agriculture development.

\section{Coffee Project: case description}

For our hypothetical case, we will assume that farmer feedback systems will be planned for and created at the beginning of the project. It is possible to retrofit feedback systems, but the best approach is to plan feedback mechanisms from the beginning of the project.

Our hypothetical Coffee Project is working in five East African countries (Burundi, Ethiopia, Kenya, Rwanda, and Tanzania) to double the incomes of one million of the three million smallholder coffee farmers in the region. The project focuses on facilitating a production shift away from 'ordinary' coffee and into 'washed' coffee for the speciality market that is expected to achieve a higher and less volatile price.

The key to unlocking a doubling of incomes is the introduction of a new wet-mill technology and a set of financial and technical inputs to use the wet mills to increase the value of harvested beans. The project:

- Works with existing or new Farmer Groups (FGs) (with approximately 600 members each) to enable them to access credit to purchase the wet mills;

- Provides FGs with training in financial management and governance;

- Provides technical training in the use of the mills; and

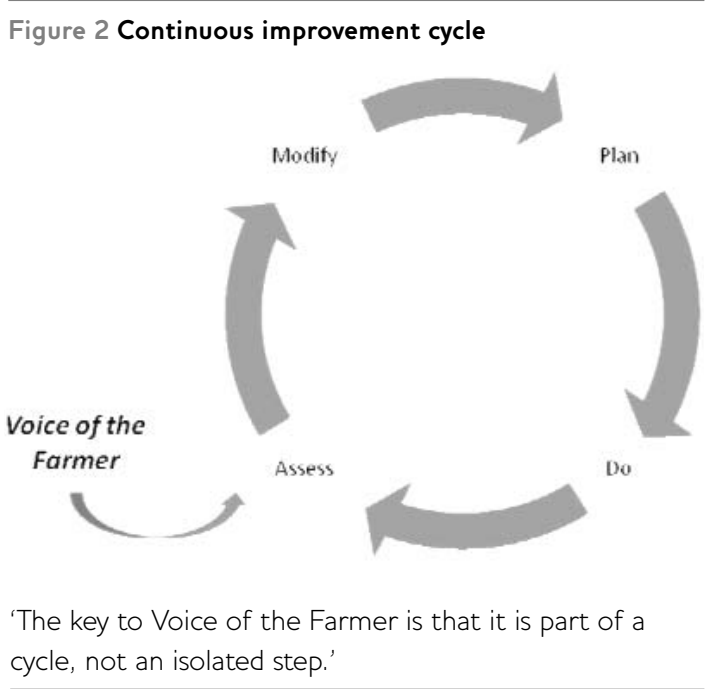

- Organises coffee buyers to provide working capital to FGs to enable them to purchase harvested coffee cherries from their members.

Participating farmers are meant to enjoy a range of direct and indirect benefits from the project, the main ones being:

- A competitive price from their FG for their harvested cherries;

- Possible wage income from employment by the FG during coffee cherry washing;

- A second payment from the FG from the sale of the washed coffee, which achieves a higher price because of the improved milling process;

- A reduction in time and labour spent in processing the coffee cherries; and

- A reduction in pollution and water usage in washing.

Demonstrated to be effective in trials, the challenge is to maintain quality through a 12-year scale-up across five countries in which 1,469 wet mills will be introduced and a correlated number of FGs, through a small army of more than 240 business advisers who each provide three years of free services to six FGs. Farmer Groups are expected to graduate from the project after three years and be selfreliant.

3 Introducing farmer voice into the Coffee Project A fundamental principle to any successful initiative is listening and acting upon the voice of the constituents. If this Coffee Project should be expected to follow that same compass and the 
opportunity to build this into the programme at the beginning, then it will be far more effective. In this situation there are three constituent groups that should be surveyed on a regular basis (see Figure 1).

The farmer, the farmer group leader, and the Project's field business adviser/superviser each have a distinct perspective and of course role in the Coffee Project, and therefore have a 'voice' that needs to be systematically monitored and measured. The information coming back through group surveys will help guide the Coffee Project through its multi-year cycle.

Figure 2 sets out the four elements in a cycle of continuous improvement for the Coffee Project. Voice of the Farmer is at the heart of the step of assessment that enables project actors to gain insights from current actions and make improvements. Voice of the Farmer involves three steps: survey, analysis and report back/ deliberation. Each is described briefly below.

\subsection{Survey}

A mantra of continuous improvement reinforces a culture of using evidence to improve performance. The success of Voice of the Farmer work can never be more than the extent to which the organisation realises a culture of evidence-based performance management. Constituent surveys both contribute to and manifest this culture. Their objective is to collect unbiased, quantitative information that provides a rational basis for helping operate the Coffee Project effectively. Surveys must be done in a transparent way and management must embrace the notion of sharing and working with the resulting information so that the organisation is always on course of doing better.

The following section gives some of the main ideas that would be addressed in each of the three constituent groups.

\subsubsection{Key questions and issues for the three constituent groups \\ 3.1.1.1 Farmers \\ - How well do the FG leaders and the Coffee Project business advisers support me? \\ - Evaluation of critical success factors like: communication, timeliness, trust, effectiveness of the education and training programmes, and business advice and guidance that is helpful and effective.}

Quality of financial training;

Quality of governance training;

- How strong is the feeling that we are making progress and improvements versus our goals?

- What are the barriers to achieving our goals?

3.1.1.2 Farmer group leaders

- How effective are we with the farmers?

- Quality of financial training;

- Quality of governance training;

- Are the goals and objectives aligned with the support provided?

- How do things look upstream in to the Coffee Project management organisation?

- Are we being provided the right support?

- How is the communication? The timeliness of support?

- How well do farmers trust us as group leaders? How well do the Coffee Project business advisers trust us?

- What are the barriers to achieving our goals?

- Transparency of decision-making.

3.1.1.3 Business advisers

- How well am I supporting the FG leaders and the farmers?

- Am I getting the right and appropriate support from the Coffee Project leadership?

- Are we effective as business advisers?

- Are we making the right progress on our goals and what indications of success do we see quantitative and qualitative?

- How well do the FG leaders and farmers trust us?

The surveys would be conducted on a 'face-toface' basis by trained field interviewers on a regular basis with a plan to hear from the three survey groups every three months. It is an ongoing pulse of the situation and is therefore a tracking system that allows the Coffee Project leadership team to monitor things with authoritative and objective information.

Collecting feedback of this type is never straightforward. Respondents may be sceptical or distrusting. They may worry that their feedback could be used against them. If confidentiality is promised - as ideally it should be - how much will respondents trust it? If possible the interviewers should be, and be seen to be, independent, but this may not be practical. The key to success is if respondents can see for themselves that the feedback is taken seriously, 
Figure 3 Performance management report card

\begin{tabular}{|c|c|c|c|c|c|c|c|c|c|c|}
\hline & 1 & 2 & 3 & 4 & 5 & 6 & 7 & 8 & 9 & 10 \\
\hline \multicolumn{11}{|l|}{$\begin{array}{l}\text { Performance ratings - Technical } \\
\text { training \& education }\end{array}$} \\
\hline \multicolumn{11}{|l|}{ Lessons and lectures } \\
\hline \multicolumn{11}{|l|}{ Projects and exercises } \\
\hline \multicolumn{11}{|l|}{ Knowledge of instructors } \\
\hline \multicolumn{11}{|l|}{ Quality of materials used } \\
\hline \multicolumn{11}{|l|}{ Instructors understood my situation } \\
\hline \multicolumn{11}{|l|}{$\begin{array}{l}\text { Overall effectiveness and quality of } \\
\text { technical training and education } \\
\text { programs }\end{array}$} \\
\hline \multicolumn{11}{|l|}{$\begin{array}{l}\text { Performance ratings - Business and } \\
\text { Financial training }\end{array}$} \\
\hline \multicolumn{11}{|l|}{ Lessons and lectures } \\
\hline \multicolumn{11}{|l|}{ Projects and exercises } \\
\hline \multicolumn{11}{|l|}{ Knowledge of instructors } \\
\hline \multicolumn{11}{|l|}{ Quality of materials used } \\
\hline \multicolumn{11}{|l|}{ Instructors understood my situation } \\
\hline \multicolumn{11}{|l|}{$\begin{array}{l}\text { Overall effectiveness and quality of } \\
\text { business and financial training } \\
\text { programs }\end{array}$} \\
\hline \multirow{2}{*}{\multicolumn{11}{|c|}{ General }} \\
\hline & & & & & & & & & & \\
\hline \multicolumn{11}{|l|}{ Trust } \\
\hline \multicolumn{11}{|l|}{ Communication } \\
\hline \multicolumn{11}{|l|}{ Accessibility of staff } \\
\hline \multicolumn{11}{|l|}{ Concern for my needs } \\
\hline \multirow{2}{*}{\multicolumn{11}{|c|}{ Overall Ratings }} \\
\hline & & & & & & & & & & \\
\hline \multicolumn{11}{|l|}{$\begin{array}{l}\text { Overall how satisfied are you with the } \\
\text { Coffee Project? }\end{array}$} \\
\hline \multicolumn{11}{|l|}{$\begin{array}{l}\text { How likely would you recommend } \\
\text { friends or relatives to participate in the } \\
\text { Coffee Project? }\end{array}$} \\
\hline $\begin{array}{l}\text { How likely would you join the Coffee } \\
\text { Project again? }\end{array}$ & & & & & & & & & & \\
\hline
\end{tabular}

then when given future opportunities they will provide feedback with greater effort and expectation. This is a process and the more it is done, and the more information is reported out and acted on, the more likely it will build on itself and progressively become more 'honest'.

We propose that each of these three surveys cover the following areas:

a Performance ratings on technical training and education

b Performance ratings on financial and business training and education

c Overall satisfaction with the Coffee Project d Demographic information

e Outcomes: quality of life measures.

Figure 3 illustrates the kind of performance management report card that the surveys will populate with data on a regular basis.

\subsection{Analysis}

While it is a significant undertaking to plan, organise and conduct three related surveys, the real fruit of this endeavour comes in the analysis, reporting and deliberation of the information. Just collecting the data is not enough. This is the trap that so many organisations fall into. The value is in what is done with the information. 
Coffee Project - Farmer Satisfaction Index

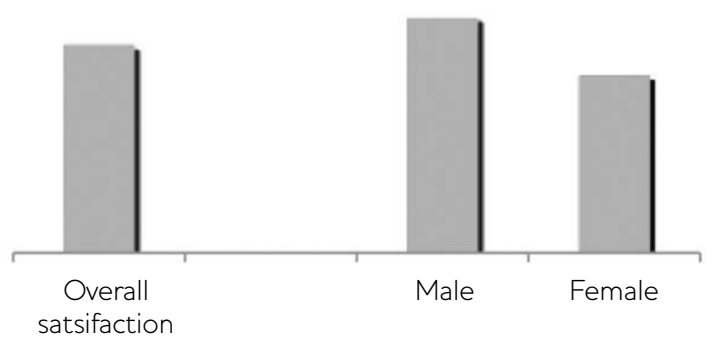

Coffee Project - Farmer Satisfaction Index (by age)

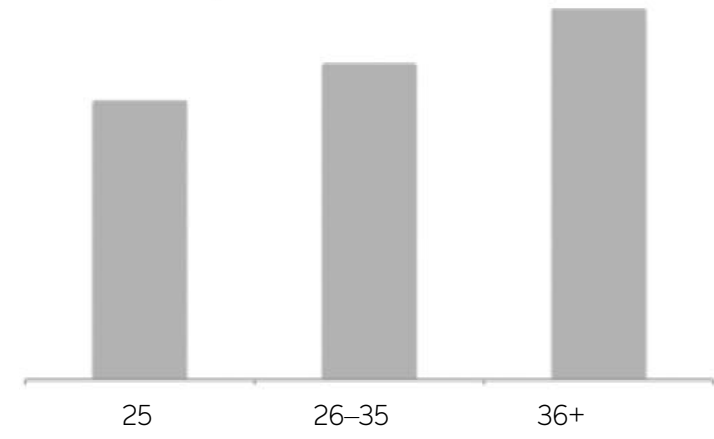

Therefore a plan and systems need to be developed to take the data in and analyse it for improvement purposes. The result of this will then help track and improve the relevance and quality of financial and governance training.

For analysis purposes it is useful to produce simple summary visualisations of the data for review and discussion by Coffee Project staff. Figure 4 provides a mock-up of the overall satisfaction disaggregated by age, gender, region, age and training. These need to be reviewed periodically, tracking the data over time for trends and responsiveness to modifications in management practices.

While not captured in these figures, Voice of the Farmer surveys of farmers, the FG leaders and the field business advisers would ask a small number of important questions that would yield evidence of wider impacts of the Coffee Project on farmers' household (i.e. is the farmer becoming too 'coffee dependent' at the expense of food and other cash crops). These questions will generate data that can be validated during the report back stage.

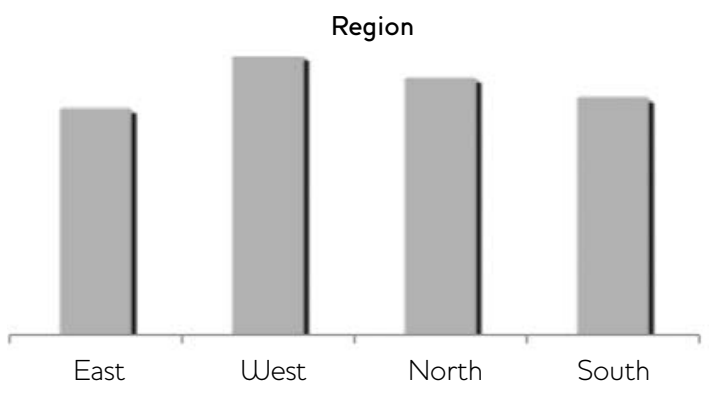

Experience + involvement

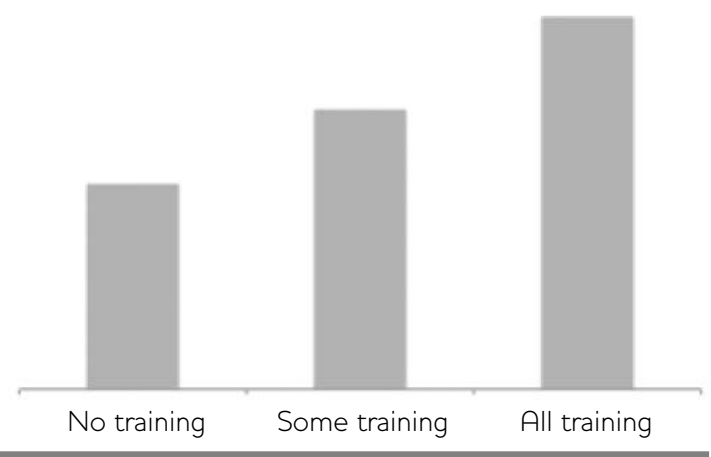

\subsection{Reporting back and deliberation}

We have emphasised that feedback must be followed up and acted upon in order to be useful and that the essential step in following through is reporting back to respondents and deliberating with them about ways to improve. Feedback data can produce important insights that can lead to performance improvements, but the highest value of feedback is for cultivating authentic conversations that begin with the survey questions and responses, but can then build out to explore solutions, reset expectations, and redefine roles and responsibilities. Mutually accountable dialogues about the project between the primary constituents of the solutions being attempted and those seeking to support them lies at the heart of effective development practice. Where project relationships are grounded in such dialogues, then problems will be solved and progress will be sustained.

In the case of the Coffee Project, project managers should plan for three sets of report backs - with farmer groups, farmer group leaders, and business advisers. The same threepart format can be applied in each case. The survey findings can be reported and discussed. 
Sharing feedback from other areas by way of comparison is a powerful way to stretch everyone's sense of what is possible, or how to improve. From this point onwards the feedback relating to the outcomes and impacts of the project are particularly valuable as they provide the farmers with a way to correlate their individual benefits to the collective actions of the project. Coffee Project managers next share their suggested improvements and possible solutions for consideration by the constituency group. At that point the conversation can be opened out to consider other possible improvements or priorities and into a collaborative process of re-planning.

\subsection{A final encouragement}

By utilising the feedback from the three sources described in this case description, the Coffee Project will raise its overall standard of performance. It will also improve the quality and transparency of deliberation, decision-making and financial management of the FGs.

But undertakings like this don't happen by themselves. The satisfaction metrics won't change by themselves (and could get worse) unless there is a robust continuous improvement effort in place. We have argued that this process begins with careful planning and a sober understanding of the challenges associated with receiving and acting on feedback.

\section{Notes}

1 See particularly Haddad et al., Jacobs, Devereux and Longhurst, Chambers and Millstone et al.

2 See President Kennedy's 'Special Message to the Congress on Protecting the Consumer Interest, March 15th, 1962' for a complete review of the set of legislation, regulation and new programmes instituted by the US federal government at that time.

3 Leading references include: Denove and Power (2006), Michelli (2008), Sewell (1998),
Considerable care needs to be given to provide managers with a 'safe space' from which to overcome the challenges to farmer feedback. Many managers will find it difficult to accept results (and not be devastated or indignant about results they disagree with). Supervisers will need to help them keep a good balance and perspective. Together, supervisers and managers must work with the results - not dismiss them to formulate remedies that can then be tested. The management team needs to take responsibility to improve - it is no one else's job. Everyone must see that measurement is a necessary but not sufficient first step. To be sufficient, organisations must take two more steps. The second step is improvements (changing behaviour). The third step is measuring again to learn if the improvements are making a difference to farmers.

If effective feedback mechanisms can be created and operated, and if managers work with the feedback to make improvements, the farmers who are meant to benefit from the project will be more independent, more stable, and more demanding of effectiveness and probity from their FG leaders. We have argued in this article that the net impact will be an improved standard of living for all.

Blanchard (2004), Kazanjian (2007), Bethune (1998), Spector and McCarthy (2005).

4 For a recent summary showing how customer satisfaction research has defined, measured and influenced quality in the automotive industry, see http://businesscenter.jdpower.com/ JDPAContent/CorpComm/News/content/ Releases/pdf/2010099-uiq2.pdf (accessed 16 July 2010). 


\section{References}

Bethune, G. (1998) From Worst to First: Behind the Scenes of Continental's Remarkable Comeback, New York: John Wiley \& Sons Inc.

Blanchard, K. (2004) Customer Mania! It's Never Too Late to Build a Customer Focused Company, New York: Free Press

Denove, C. and Power, J.D. (2006) Satisfaction: How Every Great Company Listens to the Voice of the Customer, New York: Penguin Group

J.D. Power and Associates (2009) New Homebuilder Satisfaction Study - Industry Performance 2002 to 2009 by Major Market

Kazanjian, K. (2007) Exceeding Customer Expectations, New York: DoubleDay
Michelli, J.A. (2008) The New Gold Standard: 5 Leadership Principles for Creating a Legendary Customer Experience Courtesy of the Ritz-Carlton Hotel Company, New York: McGraw-Hill Company

Sewell, C. (1998) Customers for Life: How to Turn that Onetime Buyer into a Lifetime Consumer, New York: DoubleDay

Spector, R. and McCarthy, P. (2005) The Nordstrom Way to Customer Service Excellence: A Handbook for Implementing Great Service in Your Organization, New Jersey: John Wiley \& Sons Inc. 